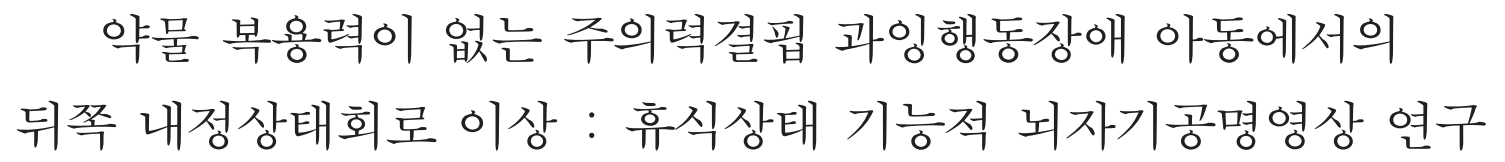

$$
\text { 최지욱 }{ }^{1)} \cdot \text { 고효진 }^{1)} \cdot \text { 우영섭 }{ }^{1)} \cdot \text { 송승훈 }^{1)} \cdot \text { 양보성 }{ }^{2)} \cdot \text { 정범석 }{ }^{3)}
$$

가톨릭대학교 의과대학 대전성모병원 정신건강의학교실, ${ }^{1)}$ 가톨릭대학교 의과대학 대전성모병원 영상의학교실, ${ }^{2)}$ 한국과학기술원 의과학대학원 ${ }^{3}$

\title{
The Abnormality of Posterior Default Mode Network in Medication-Naïve Attention-Deficit Hyperactivity Disorder Children : Resting State fMRI Study
}

\author{
Jeewook Choi, M.D., Ph.D. ${ }^{1)}$, Hyo Jin Go, M.D., Ph.D. ${ }^{1)}$, Young Sup Woo, M.D. ${ }^{1)}$, \\ Seung Hoon Song, M.A. ${ }^{1)}$, Po Song Yang, M.D., Ph.D. ${ }^{2)}$ and Bumseok Jeong, M.D., Ph.D. ${ }^{3)}$ \\ ${ }^{1)}$ Departments of Psychiatry, College of Medicine, The Catholic University of Korea, Daejeon St. Mary's Hospital, Daejeon, Korea \\ ${ }^{2}$ Department of Radiology, College of Medicine, The Catholic University of Korea, Daejeon St. Mary's Hospital, Daejeon, Korea \\ ${ }^{3)}$ Graduate School of Medical Science and Engineering, Korea Advanced Institute of Science and Technology, Daejeon, Korea
}

Objectives : Characteristic symptoms, including hyperactivity and easy distractibility, in children with attention-deficit hyperactivity disorder (ADHD) suggest that their brain status, even at rest, might differ from that of healthy children. This study was conducted in order to determine whether resting state brain activity is compromised in medication-naïve children with ADHD.

Methods : Twenty medication-naïve children with ADHD (mean age 10.3 \pm 2.5 ) and 28 age- and gender-matched healthy volunteers (mean age 10.3 \pm 2.0 ) underwent measurements for resting state brain activity using functional magnetic resonance imaging (fMRI). Among resting state related-independent components (RSICs) extracted from fMRI data using independent component analysis, a significant difference in RSICs was observed between groups, using a mixed Gaussian/gamma model.

Results : Except for IQ, which was higher in the healthy control group, no demographic difference was observed between the two groups $(\mathrm{p}<.001)$. Significantly less activation of one RSIC, which includes the bilateral precuneus/posterior cingulate cortex, occipito-temporal junction, and anterior cingulate cortex, was observed in the ADHD group, compared with the control group ( $\mathrm{p}<.05$ ).

Conclusion : An abnormal RSIC, posterior default mode network (DMN), was observed in the medication-naïve ADHD group. Results of our study suggest that abnormality of posterior DMN is one of the main pathophysiologies of ADHD.

KEY WORDS : ADHD · Default Mode Network · Functional MRI.

\section{서 론}

내정상태회로(default mode network, DMN)는 휴식, ${ }^{1)}$ 수 면,2) 마취상태' 등 외부 자극에 집중 없이 특정 인지활동을 하 지 않는 상태에서 활성화되는 회로를 말한다. 일반적으로 D-

접수완료 :2012년 2월 28일 / 심사완료 :2012년 4월 25일

Address for correspondence: Bumseok Jeong, M.D., Ph.D., Graduate School of Medical Science and Engineering, Korea Advanced Institute of Science and Technology, 291 Daehak-ro, Yuseong-gu, Daejeon 305-701, Korea

Tel : +82.42-350-4245, Fax : +82.42-221-4776

E-mail : bs.jeong@kaist.ac.kr

이 논문은 2010년 가톨릭중앙의료원 성의장학 학술연구비(C.J.) 및 한국연구재단의 뇌 과학원천기술개발사업(No.2006-05372 : J.B.) 지원을 받아 이루어졌음.
$\mathrm{MN}$ 는 휴식상태에서 $0.1 \mathrm{~Hz}$ 이하의 속도로 활동하는 것으로 특징지어진다. 주로 앞쐐기소옆(precuneus), 뒤쪽 띠이랑(posterior cingulate cortex), 내측 이마앞 피질(medial prefrontal cortex), 아래 두정피질(inferior parietal cortex) 등이 대표적 인 $\mathrm{DMN}$ 영역들이다. $\mathrm{DMN}$ 관련 연구는 특정 인지 작업이 필 요 없이 측정할 수 있다는 장점 때문에 조현병훈 아니라 치 매, ${ }^{5)}$ 주의력결핍 과잉행동장애(attention-deficit hyperactivity disorder, $\mathrm{ADHD})^{6,7)}$ 등의 다양한 뇌질환 연구 ${ }^{8}$ 에 활용되 고 있다. 최근 연구에 따르면 $\mathrm{DMN}$ 가 인지활동에도 관여하는 것으로 알려져 인지활동 중에는 활성이 억제되고 휴식상태에 는 활성화된다고 알려져 있다. Jeong과 Kubicki ${ }^{4}$ 의 연구에 의 하면 몇몇 의미관련 과제 수행시 정상 대조군에 비해 조현병 
집단에서 $\mathrm{DMN}$ 의 활성이 덜 억제되고 휴식상태에는 덜 활성 화되는 현상을 보고하였다. 따라서 집중 과제 수행시 어려움을 보일 뿐만 아니라 아무 과제도 하고 있지 않는 휴식상태에도 과 잉행동 및 산만함을 보이는 $\mathrm{ADHD}$ 의 병리생태를 규명하는데 $\mathrm{DMN}$ 이 유용할 것이다.

$\mathrm{ADHD}$ 는 학령기 아동에서 가장 흔한 정신과적 질환으로, 장 기적으로도 학업적, 사회적, 정서적 기능의 손상을 가져온다. ${ }^{9}$ $\mathrm{ADHD}$ 는 주의력결핍 과잉행동 등 겉으로 드러나는 행동만 의 문제가 아니라 뇌 구조 이상도 보고되고 있다. 최근 Choi 등이 에 의해 수행된 확산텐서영상(diffusion tensor imaging) 연구 에서는 약물을 복용하고 있는 $\mathrm{ADHD}$ 집단의 전두엽, 소뇌, 중 간 후두엽 근처의 백질 이상을 보고하였다. 또한 Lee 등1ㅣㅇㅣ 약 물 복용력이 없는 $\mathrm{ADHD}$ 집단을 대상으로 한 연구에서도 시 각 정보 처리 관련 회로인 후두엽과 측두엽 혹은 후두엽과 전 두엽을 연결하는 백질의 분할 비등방도(fractional anisotro$\mathrm{py})$ 의 저하가 보고되었다. $\mathrm{ADHD}$ 의 이러한 해부학적 이상은 뇌 기능적 이상이 있을 것임을 시사한다.

뇌기능 연구에 많이 사용되는 기능적 자기공명영상(functional magnetic resonance imaging, fMRI)의 경우 일반적 으로 정해진 인지작업을 하는 동안의 영상을 얻어 분석하게 된다. 최근에는 아무 것도 하지 않는 휴식상태(resting state)에 서 fMRI를 촬영하여 기능적 이상을 보고하는 연구들이 발 표되고 있다. Zang 등 ${ }^{12}$ 은 $\mathrm{ADHD}$ 아동에 있어서 휴식상태에 서의 fMRI 연구에서 정상 아동에 비해 DMN의 활성 강도가 감소되어 있음을 보고하였고, 성인 $\mathrm{ADHD}$ 환자들을 대상으 로 휴식상태에서의 fMRI 자료를 분석한 Castellanos 등ㄲ은, 관심영역으로 잡은 앞쪽 띠이랑(anterior cingulate cortex) 지 역과 내정상태회로 간 연결성이 감소되어 있다고 보고하면서, 이러한 연결성의 이상이 $\mathrm{ADHD}$ 의 주요 병태생리일 수 있음을 제안하였다. 또 Sun 등그는 앞쪽 띠이랑의 관심영역과 뇌의 다 른 모든 영역들과의 휴식기 기능적 연결성 분석에서, 정상 아 동에서 보이는 뒤쪽 DMN과의 역상관관계(anticorrelation)가 약물 복용력이 없는 $\mathrm{ADHD}$ 아동들에서 감소한 것을 보고하 였다. 한편, $\mathrm{ADHD}$ 청소년을 대상으로 인지작업 수행동안의 뇌 활성 연구에서는 약물치료에 의해 $\mathrm{DMN}$ 의 이상소견이 정 상화 혹은 호전된다는 보고도 있다. ${ }^{14,15)}$ 이러한 이전 연구들을 살펴보면, 주로 성인이나 청소년 환자를 대상으로 하거나, 과 거 약물 복용력이 있는 환자를 대상으로 하여, 약물이 뇌기능 의 변화에 미치는 영향을 배제할 수 없다는 취약점이 있었다. 또한 $\mathrm{ADHD}$ 의 병태생리로 관심 받아오고 있는 앞쪽 띠이랑 을 포함한 집중 회로의 이상을 바탕으로 한 이론위주(theorydriven)의 단변량적 접근이 대부분이었다. 즉 미리 정한 뇌의 한 부분을 관심영역으로 하여 이것과 상관관계를 보이는 뇌영
역들과의 회로를 구성하는 방식이므로 전체 뇌 네트워크 간의 연결성을 모두 반영할 수 없는 제한점이 있다.

따라서 본 연구에서는 약물 복용력이 없는 아동 $\mathrm{ADHD}$ 환 자들을 대상으로, 휴식상태 동안 fMRI을 촬영하여, 전체 뇌 신호를 모두 감안한 다변량적 방법인 독립요인분석(independent component analysis, ICA)방법을 이용하여 휴식상태 관련 뇌회로들(resting state networks)을 추출하고, 정상 대조 군과 비교하여 $\mathrm{ADHD}$ 병태생리를 규명하고자 하였다.

\section{방 법}

\section{1. 대 상}

가톨릭대학교 대전성모병원 소아청소년정신과 외래를 방문 하는 환아 중 6-16세의 항정신성 약물 복용력이 없는 ADHD 환아를 모집하였으며, 성별과 연령이 같은 정상아동들을 대상 으로 광고를 통해 연구에 참여할 피험자를 모집하였다. $\mathrm{ADHD}$ 진단은 Diagnostic and Statistical Manual of Mental Disorders-Fourth Edition 진단 기준을 따랐으며, 소아청소년정신 과 전문의에 의해 한국판 Kiddie-Schedule for Affective Disorders and Schizophrenia-Present and Lifetime Version $(\mathrm{K}-\mathrm{SADS}-\mathrm{PL})^{16)}$ 을 사용하여 진단하였다. 전체 지능이 70 이 상인 피험자만을 대상으로 하였으며, 모집된 대상자 중 신경학 적 질병이나 외상, 발달장애, 정신지체 및 뇌 발달에 영향을 미 칠만한 신체 질환의 기왕력이나 현병력이 없는 경우만 피험자 로 선별하였다. 또한 협소 공포증이 있거나 몸에 금속 물질이 있는 경우, 촬영에 협조할 수 없을 상태인 경우는 배제되었다. 본 연구 계획은 가톨릭대학교 대전성모병원 연구윤리심의위원 회 심의를 거쳤으며, 연구에 대해 설명 후 피험자 및 피험자 부 모의 자필 동의를 얻었다.

\section{2. 임상증상 측정}

$\mathrm{ADHD}$ 증상은 한국판 $\mathrm{ADHD}$ 평정척도(the Korean version of the ADHD Rating Scale $)^{17)}$ 를 이용하여 평가되었으며, 한국판 K-SADS-PL을 이용하여 동반된 정신질환도 평가되 었다. 모든 피험자를 대상으로 한국판 아동용 웩슬러 지능검 사(Korean Educational Developmental Institute-Wechsler Intelligence Scale for Children) ${ }^{18}$ 를 시행하여 전체지능을 측 정하였다.

\section{3. 기능적 뇌영상 촬영}

구조적 뇌 이상 감별 및 추후 분석에 이용하기 위해 $\mathrm{T} 1$ 강조 뇌영상(slice number $=170$, slice thickness $=1 \mathrm{~mm}$, field of view $=240 \times 240 \mathrm{~mm}^{2}, \mathrm{TR}=25 \mathrm{msec}, \mathrm{TE}=4.6 \mathrm{~ms}$ )을 얻었다. 이 
후 5 분간 잠들지 않은 상태에서 눈을 감은 채 아무 것도 하지 않도록 하며 기능적 자기공명영상 $(\mathrm{TR}=2000 \mathrm{msec}, \mathrm{TE}=35 \mathrm{msec}$, spatial resolution $=3.4375 \times 3.4375 \times 5 \mathrm{~mm}^{3}$, imaging matrix $=$ $64 \times 64$, field - of - view $=240 \times 240 \mathrm{~mm}^{2}$, number of slices $=27$, 210 volumes)을 얻었다.

\section{4. 기능적 뇌영상 전처리}

기능적 뇌영상은 FSL(http://www.fmrib.ox.ac.uk/fsl) 연구 집단에서 제작한 Multivariate Exploratory Linear Optimized Decomposition into Independent Components(MELO$\mathrm{DIC}$ )을 이용하였다. 촬영 초기의 장비의 신호 불안정에 의한 영향을 제거하기 위해 얻어진 210 개의 뇌영상 중 첫 5 개는 분 석에서 제외하였다. 나머지 205개의 뇌영상은 촬영 중 머리의 움직임, 기능적 뇌영상의 왜곡 등을 교정하기 위해 정합보정 (realignment) 과정, 촬영의 시간차 교정(slice timing correction)하는 과정을 거쳤다. 또한 신호 잡음을 제거하기 위해 시 간 필터 $(0.01 \mathrm{~Hz}<\mathrm{f}<0.1)$ 를 이용하여 효과적으로 휴식상태 관 련 신호만을 추출하였고, $5 \mathrm{~mm}$ 가우시안커널을 이용하여 공 간 평편화 작업을 거쳤다. 마지막으로 공간적 분해능이 좋은 $\mathrm{T} 1$ 강조영상에 기능적 뇌영상을 등록하고 이를 표준 뇌공간 으로 옮기는 과정을 거쳤다.

\section{5. 독립성분분석(independent component analysis)}

전처리를 거친 48 명의 기능적 자기공명 영상 자료를 피험자, 공간, 시간의 형태로 배열하여 독립요인분석을 실시하여 28개 의 휴식상태 관련 뇌회로(resting state related independent component, RSIC)를 추출하였다. 독립성분분석은 FSL의 MELODIC(http://www.fmrib.ox.ac.uk/analysis/research/melodic/)을 이용하여 분석하였다. 독립성분을 이루는 신호는 가 우시안 분포를 이루는 잡음과 달리 감마 분포를 따르기 때문 에 각 RSIC의 공간적 분포를 Gaussian/gamma mixture model을 이용하여 적용하여, 잡음 신호에 해당되지 않는 확률에 해당되는 부피소만을 특정 RSIC로 규정하였다. ${ }^{19)}$ 이때 피험 자 각각이 독립성분에 미치는 영향(effect size)을 계산할 수 있으며, 각 독립성분별 집단간 차이 분석은 General linear model을 이용하였다. 유의수준은 p value $<.05$ 로 하였다. ${ }^{19)}$

\section{결 과}

\section{1. 피험자 특성 및 증상}

총 50명의 피험자가 모집되었으며, 그 중 우연히 발견된 지주 막 낭종(arachnoid cyst)으로 두 명이 탈락되었으며, ADHD 20 명, 정상 대조군 28 명이 최종 피험자로 뇌영상 자료 분석에
포함되었다. 연령별, 성별, 키, 몸무게, 부모교육 수준 등에서 두 집단 간에 차이를 보이지 않았으며, $\mathrm{ADHD}$ 군에서 지능이 다소 낮게 나타났다. 한국형 $\mathrm{ADHD}$ 평정척도에서는 $\mathrm{ADHD}$ 군에서 현저한 차이를 보였다(Table 1). ADHD군 20명 중에 서 17명은 ADHD, combined type이었고, 3명은 inattentive type이었으며, 동반질환으로는, 적대적 반항장애 2명, 사회공 포증 1 명, 우울장애 1 명이었다.

\section{2. 기능적 뇌영상 결과}

추출된 28개의 ICs 중에서 12 개가 RSICs에 해당되었다(Fig. 1). 12 개의 RSICs중 단 1 개만이 $\mathrm{ADHD}$ 집단에서 유의하게 덜 활성화되었다(z=1.74, p<.05)(Fig. 2). 이 RSIC는 양쪽 쐐기앞 소엽(precuneus), 뒤쪽 띠이랑(posterior cingulate cortex) 및 후두-측두 연결부위(occipito-temporal junction) 등으로 구성된 뒤쪽 내정상태회로(posterior DMN: IC 6)로 이었다. Right ventral fronto-parietal RSIC(IC 2) 또한 집단 간 차이 를 보이는 경향( $\mathrm{z}=1.15, \mathrm{p}=.06)$ 이 관찰되었다. 이러한 차이는 12 개의 독립성분을 대상으로 각각 집단비교를 하였으므로 이를 교정할 필요가 있으며, 이때의 유의수준은 $\mathrm{p}$ value $<.0042$ $(0.05 / 12)$ 이나 본 연구 결과는 이에 미치지 못하였다.

\section{고 찰}

본 연구에서는 6에서 16 세 사이의 약물 복용력이 없는 $\mathrm{AD}$ $\mathrm{HD}$ 집단 및 정상 대조군을 대상으로 독립성분분석을 이용하 여 12 개의 RSIC를 추출하여, 두 집단 간 각 RSIC의 활성 정 도를 비교하였다. 그 결과, 약물 복용력이 없는 $\mathrm{ADHD}$ 집단은 추출된 12 개의 RSIC들 중에서 posterior $\mathrm{DMN}$ 의 이상이 있 음을 확인하였다. 본 연구 결과는 약물 복용 중인 $\mathrm{ADHD}$ 집

Table 1. Subjects' characteristics

\begin{tabular}{lcc}
\hline & $\begin{array}{c}\text { ADHD } \\
(\mathrm{N}=20)\end{array}$ & $\begin{array}{c}\text { Health control } \\
(\mathrm{N}=28)\end{array}$ \\
\hline Gender (male : female) & $16: 4$ & $20: 8$ \\
Age, $y$ & $10.3 \pm 2.5$ & $10.3 \pm 2.0$ \\
Height, cm & $142.2 \pm 15.8$ & $143.8 \pm 12.2$ \\
Weight, $\mathrm{kg}$ & $40.8 \pm 18.9$ & $41.9 \pm 12.7$ \\
Full scale IQ* & $93.8 \pm 9.4$ & $116.2 \pm 11.0$ \\
$\quad$ Performance* & $92.8 \pm 12.5$ & $111.2 \pm 14.3$ \\
$\quad$ Verbal* & $97.8 \pm 11.4$ & $113.1 \pm 14.7$ \\
Father's education, y & $14.6 \pm 2.6$ & $14.8 \pm 2.2$ \\
Mother's education, y & $13.5 \pm 2.0$ & $14.5 \pm 2.2$ \\
Korean ADHD Rating Scale* & $41.2 \pm 7.1$ & $6.9 \pm 4.6$ \\
\hline
\end{tabular}

Fisher's exact test for gender and Student $t$ test for the rest variables. * : statistically significant $(p<.05)$. ADHD : attention-deficit hyperactivity disorder 


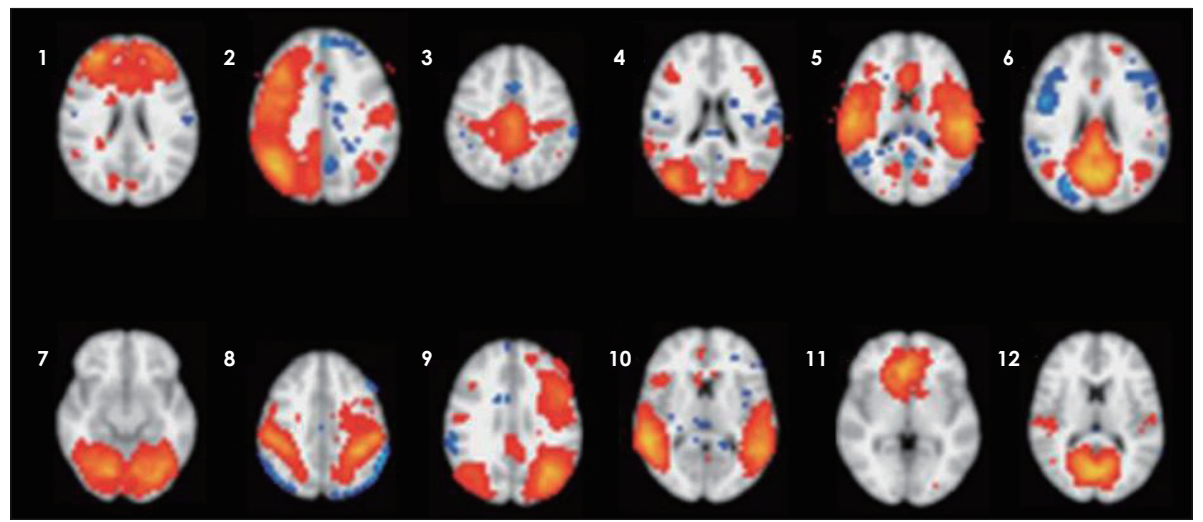

Fig. 1. Resting state related independent components (IC). IC 1 : frontal, IC2 : right ventral fronto-parietal, IC 3 : part of motor, IC4 : extrastriate (or a part of posterior DMN), IC5 : cingulo-opercular, IC6 : Posterior default mode (posterior cingulate cortex, Precuneus), IC7 : V1/V2, IC8 : Dorsal fronto-parietal, IC9 : Left ventral fronto-parietal, IC10 : a part of posterior DMN (precuneus, temporooccipital part), IC 11 : Anterior default mode, IC $12: \mathrm{V} 1$. Red color indicates independent component-related region. Blue color means anticorrelated regions with independent component. DMN : default mode network
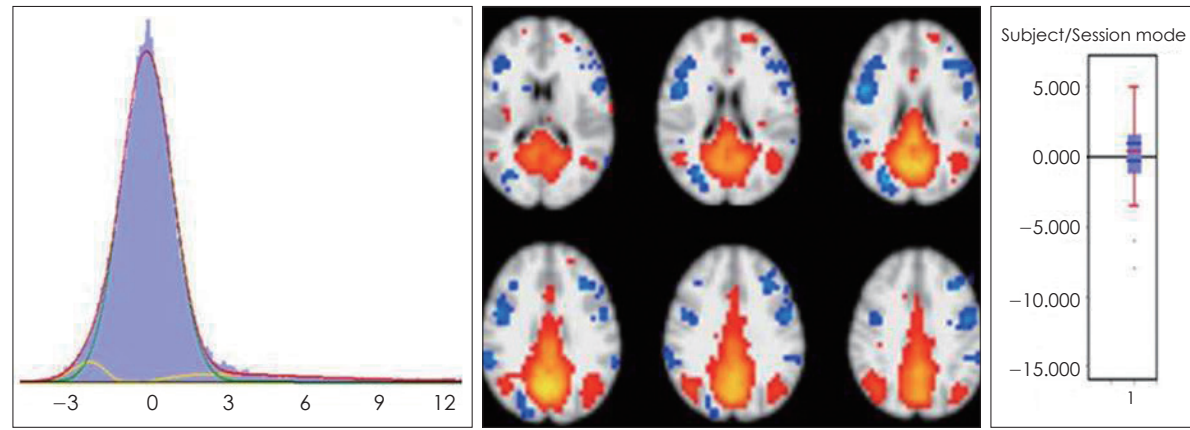

Fig. 2. The resting state related IC (IC 6 in Fig. 1) showing less activation in drug-naïve ADHD patients among 12 RSICs. Left : Gaussian/ gamma mixture model (red line), Gaussian model (green line), Gamma model (yellow line). Middle : Spatial map of the posterior default mode network including bilateral precuneus/posterior cingulate cortex and occipito-temporal junction. Radiologic orientation (left is right). Right: Boxplot showing the relative effect size across the different subjects. Red color indicates independent componentrelated region. Blue color means anticorrelated regions with independent component

단을 대상으로 한 연구 ${ }^{67,20)}$ 와 일치하여 posterior $\mathrm{DMN}$ 의 이 상이 $\mathrm{ADHD}$ 의 주요 병태생리임을 시사한다.

구조적 뇌영상 연구들에 따르면, $\mathrm{ADHD}$ 에서 전전두엽이나 선조체뿐 아니라 ${ }^{21)}$ posterior DMN, 특히 뒤쪽 띠이랑의 회백 질 이상이 있다고 보고하였다. ${ }^{22,23)}$ 이는 posterior DMN가 구 조적으로 뿐 아니라, 기능적으로도 이상이 있음을 시사한다. 최 근 $\mathrm{fMRI}$ 를 이용한 연구에 따르면, Stroop검사와 같은 인지기 능 수행 중 관찰되어야 할 $\mathrm{DMN}$ 의 기능 억제가 $\mathrm{ADHD}$ 에서 는 덜 되는 기능적 이상을 보고하였다. ${ }^{14)}$ 뿐만 아니라 $\mathrm{ADHD}$ 에서는 휴식상태에도 주의력 관련 영역으로 알려진 앞쪽 띠이 랑과 $\mathrm{DMN}$ 와의 연결성이 저하되어 있다는 보고 ${ }^{7)}$ 도 있다. 이 러한 연구들은 $\mathrm{ADHD}$ 가 주의력 관련 회로의 기능에 이상이 있다는 관점에서 주의력 관련 인지작업 혹은 휴식상태 동안 의 내정상태영역의 역할 규명에 초점이 맞추어져 있었다. 하지 만 휴식상태에서 주의력 관련 회로만을 대상으로 분석하는 방식은 뇌기능 전체의 많은 다른 정보들을 간과할 수 있는 위 험이 있다. 따라서 특정한 뇌기능의 회로만을 보는 이론 지향
적 접근(theory driven approach)보다 어떤 목적 없이 시간을 보내는 동안 뇌 전체 활동 모두를 이용하여 설명하는 자료 지 향적 접근(data driven approach)가 정보의 소실을 최대한 줄 이면서 있는 그대로의 뇌기능 상태를 최대한 반영한다고 볼 수 있다. 본 연구에서는 잡신호를 제거하고 나서 남은 모든 휴 식상태를 12 개의 독립성분으로 구분하여 각각을 집단 간 비교 하였기 때문에 자료 지향적 접근 방법의 장점을 최대한 살렸 다. 따라서 본 연구를 통해 그 동안 단순히 특정 회로만을 본 이전 연구 결과를 통해 제기된 posterior $\mathrm{DMN}$ 의 이상이 $\mathrm{A}$ $\mathrm{DHD}$ 의 주요 병태생리임을 좀 더 명확하게 규명할 수 있게 되 었다. 향후 연구에서는 특정 회로의 활성 이상이 다른 회로와 의 연결성에 어떤 영향을 미치는지와 각 회로 간 연결성 ${ }^{24)}$ 을 통합적으로 규명할 필요가 있다.

본 연구의 결과인 $\mathrm{DMN}$ 의 이상, 이전 연구 결과인 휴식상 태 $^{14,20)}$ 및 인지작업 동안 ${ }^{7)}$ 의 인지영역과 $\mathrm{DMN}$ 와의 기능적 연 결성 저하를 통합해보면 $\mathrm{ADHD}$ 의 병태생리가 단순히 특정 인지회로 만의 문제가 아니라, 다양한 뇌 회로들 간의 서로 상 
호 작용 과정에서의 문제가 보다 근본적인 병태생리의 원인일 수 있으며, 그 중 $\mathrm{DMN}$ 의 기능 이상이 핵심 문제일 수 있음을 시사한다. 임상적으로 $\mathrm{ADHD}$ 아동에서 특정 인지 작업을 하 고 있지 않는 중에도 부산한 모습이나, 인지과제 수행시 보이 는 심한 반응 편차(response variability)나 과제 수행 중 순간 멍하니 깜빡하는(attentional lapses) 현상 ${ }^{25)}$ 등이 DMN의 이 상 및 관련 인지회로와의 상호 작용의 이상으로 설명되고 이 해 될 수 있다.

또 다른 궁금증은, 이러한 $\mathrm{ADHD}$ 에서 $\mathrm{DMN}$ 의 이상이 약 물치료에 의해 어떠한 영향을 받게 되는가 하는 것이다. 다양 한 기간 약물치료에 노출된 $\mathrm{ADHD}$ 집단을 대상으로 한 연구 들에서, 여전히 정상 대조군에 비해 $\mathrm{DMN}$ 의 이상을 보고하기 도 하고, ${ }^{6,70)}$ 약물치료 효과로 인지작업 동안 $\mathrm{DMN}$ 의 활성을 정상화하였다는 보고들도 있다. ${ }^{14,15,26)}$ 이러한 다양한 연구 결 과는, 휴식상태에 얻은 자료인지 여부 및 수행한 인지작업의 종류뿐 아니라 약물의 종류, 용량, 사용 기간 등에 따라 휴식 상태회로의 활성에 영향이 다르게 나타날 수 있음을 시사한 다. 그러나 본 연구에서는 약물 복용력이 전혀 없는 환자군을 대상으로 함으로써 약물 효과로 인한 영향력을 배제하였으며, 향후 약물의 단기적 혹은 장기적 효과에 대한 보다 과학적인 연구들을 위한 유용한 기초자료가 될 것으로 기대된다.

한편, 본 연구에서 유의수준에 도달하지는 못했지만 전두두정엽 회로(IC 2)의 활성이 $\mathrm{ADHD}$ 집단에서 감소하는 경향 을 보였다. 어릴 적 $\mathrm{ADHD}$ 로 진단받은 환자들을 33년간 전향 적으로 관찰한 구조적 뇌영상 결과에 따르면 전두-두정엽 관 련 뇌영역의 피질 두께가 정상 대조군에 비해 여전히 얇았으며, 증상이 호전된 집단에서는 그렇지 않은 집단에 비해 전두엽 쪽의 피질 두께가 더 두꺼운 것으로 보고하였다. ${ }^{27)}$ 이러한 결 과는 $\mathrm{ADHD}$ 의 전두-두정엽 회로 이상은 약물 치료에 의해 기 능적 이상이 교정되며 ${ }^{14)}$ 장기적으로 성공적 치료를 통해 구조 적 이상 또한 호전될 수 있음을 시사한다.

흥미롭게도, 뒤쪽 내정상태회로의 이상은 $\mathrm{ADHD}$ 뿐 아니 라 조현병, 알츠하이머 등 다른 여러 정신질환들에서도 보고 되었다. ${ }^{8)}$ 그러므로 이것이 $\mathrm{ADHD}$ 의 특이한 병태생리인가에 대 한 규명이 필요하다. 최근 Christakou 등 ${ }^{28)}$ 은 $\mathrm{ADHD}$ 와 자폐 증 환자를 대상으로 지속적 주의력 작업을 하는 동안 fMRI를 촬영한 결과, 두 집단 모두에서 내정상태의 활성이 정상대조집 단에 비해 증가되어 있었다고 보고하였다. 이러한 결과들은 인 지작업을 할 때와 휴식상태일 때 관련 영역이 관여하는 정도 에 따라 달라질 수 있음을 감안하더라도 휴식상태의 DMN의 이상이 $\mathrm{ADHD}$ 만의 특징인지는 명확하지 않다. 물론 그동안 의 $\mathrm{ADHD}$ 대상군에서 구조적 뇌자기공명영상 연구 결과들, 단일광자 단층촬영, 양전자 방출 단층촬영, 기능적 자기공명
영상 연구 결과들, 확산텐서영상 연구 결과들 등을 종합하여 각 질환들의 뇌기능적인 특이성을 이해할 필요가 있겠다. 또 한, 겉으로 드러나는 행동이나 표현양상 등을 기준으로 질환 을 진단하는 현상학적인 진단체계를 따르고 있는 현 정신과 학의 질환개념에 대한 새로운 접근, 즉 각각의 뇌기능들의 이 상과 그들의 조합에 따라 표현양상이 달라질 수 있는 보다 근 본적인 병태생리학적 측면에서의 질환에 대한 이해가 필요할 수도 있을 것이다. 본 연구에서는 제한적이나, 앞으로 이러한 의문들에 대한 이해를 위해, 추후 연구에서는 휴식상태뿐 아 니라 다양한 인지작업 동안의 기능적 뇌영상을 얻는 것이 필 요하며, 아울러 $\mathrm{DMN}$ 활성화 연구뿐 아니라 다른 회로들 간 연결성 연구, 다양한 영상연구도구들의 접목을 이용하여, 다 른 발달성 뇌질환들과의 비교 연구 등을 통해 $\mathrm{ADHD}$ 의 특이 한 병태생리를 좀더 명확하게 규명할 필요가 있다.

본 연구의 강점으로는, 이론 위주의 가설 검증이 아니라 독 립 요인 분석방법을 이용한 접근으로 이전 연구와 일치하는 결 과를 얻었다는 점, 약물 복용력이 전혀 없는 대상군을 모집함 으로써 약물의 장, 단기 효과로 인한 영향력을 배제하였다는 점, 그리고 임상적으로 가장 전형적인 $\mathrm{ADHD}$ 문제로 진료실을 찾게 되는 대표적인 연령대인 6-16세 아동을 대상으로 한 연 구라는 점 등을 들 수 있다. 그러나 본 연구 결과만으로 $\mathrm{ADHD}$ 의 병태생리를 이해하고 해석하는데 다음의 몇 가지 제한점 이 있다. 첫째, 본 연구 결과에는 뒤쪽 내정상태회로의 이상이 $\mathrm{ADHD}$ 증상 정도와 어떤 관련이 있는지에 대한 결과가 없었 다. 이는 본 연구에서 사용한 mixed Gaussian/gamma model 에서는 증상과의 상관관계를 분석할 수 없는 제한점이 있다. 물론 연구 과정에서 명확한 선정 기준을 위해 반구조화된 면 담을 통한 진단 및 소아청소년정신과 전문가의 확진 과정을 거 쳤고, 두 집단 간의 임상 척도에서도 뚜렷하게 큰 차이를 보였 으나, 추후 새로운 연구 분석 방법의 개발을 통해 증상 및 인 지기능 등과 내정상태회로 이상과의 보다 직접적인 연관성을 규명하여 할 것이다. 둘째, 두 집단 간 전체 지능이 유의미한 차 이가 있었다는 점이다. 하지만 $\mathrm{ADHD}$ 의 상대적인 지능 저 하는 주의력 저하를 비롯한 질병의 특성을 반영한 결과이기 도 하다. 따라서 이를 보정하는 것은 $\mathrm{ADHD}$ 의 특성을 제거할 위험성이 있다. ${ }^{29)}$ 셋째, 12 개의 독립요인별로 비교한 것에 대한 다중비교에 대한 보정을 한 후에는 유의미한 차이를 보이지 않았기 때문에 이에 대한 유의가 필요하다. 마지막으로, 본 연 구의 대상군 수가 대규모 연구가 아니라는 점이다. 국내 연구 여건과 연구비의 제한 등을 고려할 때 본 연구가 뇌영상 연구 로는 적은 수는 아니나, 향후 성별, 연령별, 진단 세부 아형별 충분한 수를 대상으로 한 대규모 연합 연구가 필요하다. 


\section{결 론}

주의력결핍 과잉행동장애 아동에서의 휴식상태 뇌 회로의 이상을 규명하고자, 본 연구에서는 6에서 16 세 사이의 약물 복용력이 없는 $\mathrm{ADHD}$ 집단 및 정상 대조군을 대상으로 휴식 상태 fMRI를 촬영하였다. 독립성분분석을 이용하여 12 개의 $\mathrm{RSIC}$ 를 추출하였고, 두 집단 간 각 $\mathrm{RSIC}$ 의 활성정도를 비교 하였다. 그 결과, $\mathrm{ADHD}$ 집단은 추출된 12 개의 $\mathrm{RSIC}$ 들 중에 서 posterior $\mathrm{DMN}$ 의 이상이 있음을 확인하였다. 본 연구 결 과는 posterior $\mathrm{DMN}$ 의 이상이 $\mathrm{ADHD}$ 의 주요 병태생리임을 시사한다.

중심 단어:주의력결핍 과잉행동장애 - 내정상태회로·기능적 자기공명영상.

\section{References}

1) Gusnard DA, Raichle ME, Raichle ME. Searching for a baseline: functional imaging and the resting human brain. Nat Rev Neurosci 2001;2:685-694.

2) Dang-Vu TT, Schabus M, Desseilles M, Albouy G, Boly M, Darsaud A, et al. Spontaneous neural activity during human slow wave sleep. Proc Natl Acad Sci U S A 2008;105:15160-15165.

3) Greicius MD, Kiviniemi V, Tervonen O, Vainionpää V, Alahuhta S, Reiss AL, et al. Persistent default-mode network connectivity during light sedation. Hum Brain Mapp 2008;29:839-847.

4) Jeong B, Kubicki M. Reduced task-related suppression during semantic repetition priming in schizophrenia. Psychiatry Res 2010; 181:114-120.

5) Zhang Z, Liu Y, Jiang T, Zhou B, An N, Dai H, et al. Altered spontaneous activity in Alzheimer's disease and mild cognitive impairment revealed by Regional Homogeneity. Neuroimage 2012;59: 1429-1440.

6) Cao X, Cao Q, Long X, Sun L, Sui M, Zhu C, et al. Abnormal resting-state functional connectivity patterns of the putamen in medication-naïve children with attention deficit hyperactivity disorder. Brain Res 2009;1303:195-206.

7) Castellanos FX, Margulies DS, Kelly C, Uddin LQ, Ghaffari M, Kirsch A, et al. Cingulate-precuneus interactions: a new locus of dysfunction in adult attention-deficit/hyperactivity disorder. Biol Psychiatry 2008;63:332-337.

8) Broyd SJ, Demanuele C, Debener S, Helps SK, James CJ, SonugaBarke EJ. Default-mode brain dysfunction in mental disorders: a systematic review. Neurosci Biobehav Rev 2009;33:279-296.

9) Barkley RA. Attention-deficit hyperactivity disorder: a handbook for diagnosis and treatment. 3rd ed. New York: The Guilford Press; 2006.

10) Choi J, Lim MH, Lee C, Park JK, Son J, Shim SH, et al. Comparison of diffusion tensor imaging in attention deficit hyperactivity disorder boys with or without comorbid tic disorders. J Korean Neuropsychiatr Assoc 2008;47:493-502.

11) Lee S, Jeong B, Go HJ, Yang PS, Kwon MJ, Choi J. Occipito-temporal connectivity in medication-naïve ADHD children: preliminary diffusion tensor imaging study. J Korean Neuropsychiatr Assoc 2009;
48:344-351.

12) Zang YF, He Y, Zhu CZ, Cao QJ, Sui MQ, Liang M, et al. Altered baseline brain activity in children with ADHD revealed by restingstate functional MRI. Brain Dev 2007;29:83-91.

13) Sun L, Cao Q, Long X, Sui M, Cao X, Zhu C, et al. Abnormal functional connectivity between the anterior cingulate and the default mode network in drug-naïve boys with attention deficit hyperactivity disorder. Psychiatry Res 2012;201:120-127.

14) Peterson BS, Potenza MN, Wang Z, Zhu H, Martin A, Marsh R, et al. An FMRI study of the effects of psychostimulants on defaultmode processing during Stroop task performance in youths with ADHD. Am J Psychiatry 2009;166:1286-1294.

15) Rubia K, Smith AB, Halari R, Matsukura F, Mohammad M, Taylor E, et al. Disorder-specific dissociation of orbitofrontal dysfunction in boys with pure conduct disorder during reward and ventrolateral prefrontal dysfunction in boys with pure ADHD during sustained attention. Am J Psychiatry 2009;166:83-94.

16) Kim YS, Cheon KA, Kim BN, Chang SA, Yoo HJ, Kim JW, et al. The reliability and validity of Kiddie-Schedule for Affective Disorders and Schizophrenia-Present and Lifetime Version-Korean version (K-SADS-PL-K). Yonsei Med J 2004;45:81-89.

17) So YK, Noh JS, Kim YS, Ko SG, Koh YJ. The reliability and validity of Korean parent and teacher ADHD rating scale. J Korean Neuropsychiatr Assoc 2002;41:283-289.

18) Kwak KJ, Park HW, Kim CT. A study for the standardization of Korean WISC-III (I). Korean J Dev Psychol 2002;15:19-33.

19) Beckmann CF, Smith SM. Probabilistic independent component analysis for functional magnetic resonance imaging. IEEE Trans Med Imaging 2004;23:137-152.

20) Qiu MG, Ye Z, Li QY, Liu GJ, Xie B, Wang J. Changes of brain structure and function in ADHD children. Brain Topogr 2011;24:243-252.

21) Valera EM, Faraone SV, Murray KE, Seidman LJ. Meta-analysis of structural imaging findings in attention-deficit/hyperactivity disorder. Biol Psychiatry 2007;61:1361-1369.

22) Makris N, Biederman J, Valera EM, Bush G, Kaiser J, Kennedy DN, et al. Cortical thinning of the attention and executive function networks in adults with attention-deficit/hyperactivity disorder. Cereb Cortex 2007;17:1364-1375.

23) Carmona S, Vilarroya O, Bielsa A, Trèmols V, Soliva JC, Rovira M, et al. Global and regional gray matter reductions in ADHD: a voxel-based morphometric study. Neurosci Lett 2005;389:88-93.

24) Castellanos FX, Proal E. Large-scale brain systems in ADHD: beyond the prefrontal-striatal model. Trends Cogn Sci 2012;16:17-26.

25) Sonuga-Barke EJ, Castellanos FX. Spontaneous attentional fluctuations in impaired states and pathological conditions: a neurobiological hypothesis. Neurosci Biobehav Rev 2007;31:977-986.

26) Wong CG, Stevens MC. The effects of stimulant medication on working memory functional connectivity in attention-deficit/hyperactivity disorder. Biol Psychiatry 2012;71:458-466.

27) Proal E, Reiss PT, Klein RG, Mannuzza S, Gotimer K, RamosOlazagasti MA, et al. Brain gray matter deficits at 33-year followup in adults with attention-deficit/hyperactivity disorder established in childhood. Arch Gen Psychiatry 2011;68:1122-1134.

28) Christakou A, Murphy CM, Chantiluke K, Cubillo AI, Smith AB, Giampietro V, et al. Disorder-specific functional abnormalities during sustained attention in youth with Attention Deficit Hyperactivity Disorder (ADHD) and with Autism. Mol Psychiatry 2012. [Epub ahead of print]

29) Dennis M, Francis DJ, Cirino PT, Schachar R, Barnes MA, Fletcher JM. Why IQ is not a covariate in cognitive studies of neurodevelopmental disorders. J Int Neuropsychol Soc 2009;15:331-343. 